\title{
ETIKA DALAM PERSPEKTIF FILSAFAT ISLAM
}

\author{
Nilda Miftahul Janna ${ }^{1}$, Aryanti ${ }^{2}$, \\ Dosen Pembimbing : Ibnu Hajar Sainuddin ${ }^{3}$ \\ ${ }^{1}$ Sekolah Tinggi Agama Islam (STAI) Darul Dakwah Wal-Irsyad (DDI) Kota Makassar, Indonesia \\ Email: nildamiftahuljanna@gmail.com \\ ${ }^{2}$ Sekolah Tinggi Agama Islam (STAI) Darul Dakwah Wal-Irsyad (DDI) Kota Makassar, Indonesia \\ Email: aryantialfi223@gmail.com \\ ${ }^{3}$ Sekolah Tinggi Agama Islam (STAI) Darul Dakwah Wal-Irsyad (DDI) Kota Makassar, Indonesia \\ Email: ibnuhajar@staiddimakassar.ac.id
}

\begin{abstract}
ABSTRAK
Etika ialah filsafat tentang tindakan manusia sebagai manusia (human action). Dalam perspektif filsafat, etika merupakan penyelidikan filsafat mengenai kewajiban-kewajiban manusia serta tingkah laku manusia dilihat dari segi baik dan buruknya tingkah laku tersebut. Etika juga mempunyai sifat yang sangat mendasar yaitu sifat kritis. Secara umum dapat dikatakan bahwa etika adalah filsafat tentang tindakan manusia sebagai manusia. Suatu tindakan itu mempunyai nilai etis bila dilakukan oleh manusia dan dalam kerangka manusiawi. Jelas bahwa etika itu berurusan secara langsung dengan tindakan atau tingkah laku manusia. Tingkah laku manusiawi ini bukan tingkah laku yang tidak ada artinya, tetapi yang mengejar nilai-nilai kebaikan.
\end{abstract}

\section{Kata Kunci : Etika, Perspektif, Filsafat, Islam}

\section{A. PENDAHULUAN}

Etika merupakan suatu hal yang selalu menarik dan tidak pernah berakhir untuk diperbincangkan, karena etika merupakan aturan yang sangat penting dalam tatanan kehidupan manusia. Tanpa etika atau moralitas, manusia akan meninggalkan hati nuraninya. Manusia tidak dapat membedakan mana yang baik dan mana yang tidak baik. sebagai makhluk yang memiliki kemampuan berpikir, manusia memiliki kedudukan khusus di antara makhluk lain. hal itu sebagaimana dengan jelas termaktub dalam al-Qur'an surah al-baqarah ayat 33-34. Etika berasal dari bahasa Yunani yaitu ethos yang berarti habitat, kebiasaan, akhlak, watak. Dalam bahasa Inggris etika diartikan sebagai ethic dan etiquette (sopan santun). Namun kedua kata tersebut memiliki perbedaan dalam penerapannya. Misal, etiket membahas tentang moral ataupun perilaku yang boleh atau tidak boleh dilakukan. Sedangkan etika lebih kepada tampilan dalam manusia. Filsafat memasukkan etika dalam cabang aksiologi, bersamaan dengan estetika. Dan pada artikel ini akan dibahas tentang etika dalam perspektif filsafat islam. etika merupakan salah satu cabang dari kajian filsafat, maka sangat perlu untuk mengupas tuntas tentang permasalahan etika yang bersandarkan pada ruang lingkup filsafat, khususnya dalam perspektif filsafat Islam. Dari perspektif ini dapat diketahui pandangan para pemikir atau filsuf Muslim terutama dari pandangan al-Farabi, Ibnu Miskawaih, dan al-Ghazali tentang etika. Mereka merupakan filsuf-filsuf yang memang fokus pada kajian-kajian tentang etika. ${ }^{1}$

\footnotetext{
${ }^{1}$ K. Bertens, Etika, (Yogyakarta: Kanisus, 2013), 3.
} 


\section{B. PEMBAHASAN}

\section{Etika Perspektif Filsafat Islam}

Sebelum kita lebih jauh membahas tentang etika dalam perspektif filsafat Islam, maka ada baiknya terlebih dahulu kita memahami tentang korelasi etika dengan agama, yang dapat dilihat dari dalam sudut pandang Islam. Franz Magnis Suseno menjelaskan bahwa etika memang tidak dapat menggantikan agama. Tetapi di lain pihak etika juga tidak bertentangan dengan agama, bahkan sangat diperlukan. Mengapa ?, Ada dua masalah dalam bidang moral agama yang tidak dapat dipecahkan tanpa menggunakan metode etika yaitu Pertama, masalah interpretasi terhadap perintah atau hukum yang termuat dalam wahyu. Kedua, bagaimana masalah moral yang baru yang tidak langsung dibahas dalam wahyu dapat dipecahkan sesuai dengan semangat agama itu. ${ }^{2}$

Tidak dapat disangkal bahwa etika tidak dapat menggantikan agama. Agama merupakan hal yang tepat untuk memberikan orientasi moral manusia. Penganut agama menemukan orientasi dasar kehidupan dalam agama yang diyakininya. Akan tetapi agama itu memerlukan keterampilan etika agar dapat memberikan orientasi, bukan sekadar indoktrinasi. Etika mendasarkan diri pada argumentasi rasional semata-mata, sedangkan agama pada wahyunya sendiri. Oleh karena itu, ajaran agama hanya terbuka pada mereka yang mengakuinya sedangkan etika terbuka bagi setiap orang dan dari semua agama dan juga dari pandangan manapun. Etika Islam adalah usaha yang mengatur dan mengarahkan manusia kejenjang akhlak yang luhur dan meluruskan perbuatan manusia dibawah pancaran sinar petunjuk Allah SWT. Untuk menuju keridhoan-Nya. ${ }^{3}$

Dalam Islam, etika diistilahkan dengan akhlak yang berasal dari bahasa Arab al-akhlak (al-khuluq) yang berarti budi pekerti, tabiat atau watak. Dalam al-Qur'an disebutkan bahwa "Sesungguhnya engkau Muhammad berada di atas budi pekerti yang agung". Oleh karena itu, etika dalam Islam identik dengan ilmu akhlak, yakni ilmu tentang keutamaan-keutamaan dan bagaimana cara mendapatkannya agar manusia berhias dengannya, dan ilmu tentang hal yang hina bagaimana cara menjauhinya agar manusia terbebas dari padanya. Etika di lain pihak, seringkali dianggap sama dengan akhlak. Persamaannya memang ada, karena keduanya membahas masalah baik buruknya tingkah laku manusia, akan tetapi akhlak lebih dekat dengan kelakuan atau budi pekerti yang bersifat aplikatif, sedangkan etika lebih cenderung kepada landasan filosofinya, yang membahas ilmu tentang apa yang baik dan apa yang buruk. $^{4}$

Dalam beberapa literatur Islam disebut sebagai falsafah akhlaqiyyah sering terabaikan dari perhatian para pemikir Islam. Pandangan semacam itu jelas didasari suatu keyakinan, bahwa seluruh kandungan al-Qur'an merupakan etos muslim dalam kehidupanya, sehingga seluruh disiplin ilmu dalam Islam bersumber dari padanya, yang oleh karenanya seluruh ilmu tersebut dianggap mengandung unsur-unsur akhlak yang bisa menjadi rujukan dalam nilainilai etis. Namun, pandangan lain menguraikan upaya perumusan etika dalam sejarah Islam dilakukan oleh beberapa pemikir dari berbagai cabang pemikiran termasuk di dalamnya ulama hukum (syariat atau eksoteris), para teolog, para mistikus, dan para filosof.

\footnotetext{
${ }^{2}$ Franz Magnis Suseno, Etika Dasar..., hlm. 16.

${ }^{3}$ Hamzah Yakub, Etika Islam, (Bandung: Diponogoro, 1981), hal 14

${ }^{4}$ Anton M. Moeliono (Penyunting Penyelia), Kamus Besar Bahasa Indonesia. (Jakarta: Balai Pustaka, 1989), hlm. 15. \& Ibid.
} 
Etika dalam Islam merupakan misi kenabian yang paling utama setelah pengesaan Allah Swt. (al-tauhid). Dalam hal ini Rasulullah Saw. pernah bersabda: "Bahwasanya aku diutus untuk menyempurnakan akhlak yang baik". Dalam tataran khazanah keilmuwan Islam kaitan filsafat dengan etika biasanya disebut dengan filsafat praktis. Ia menempati bagian penting dalam diskursus pemikiran Islam klasik. Filsafat praktis itu sendiri berbicara tentang segala sesuatu bagaimana seharusnya, yang berdasar kepada filsafat teoretis, yakni pembahasan tentang segala sesuatu sebagaimana adanya. Kajian tentang etika memiliki keunikan tersendiri dan disiplin ilmu yang berdiri sendiri. Sehingga gairah para ilmuwan muslim untuk membahas lebih terperinci pada bidang ilmu yang sangat krusial dalam Islam ini, melahirkan banyak karya yang dapat dijadikan sumber rujukan primer maupun sekunder. ${ }^{5}$

Dalam Lisan al-'Arab, dijelaskan bahwa al-Akhlaq bentuk jamak dari mufrad (kata tunggal) khulqun atau khuluqun yang bersinonim dengan kata al-thab'u (tabiat atau karakter) dan al-sajiyyat (tabiat, perangai, dan tingkah laku). Akhlak atau moral merupakan gambaran batin manusia berupa sifat-sifat kejiwaannya. Munculnya perbedaan itu memang sulit diingkari baik karena pengaruh Filsafat Yunani kedalam dunia Islam maupun karena narasi ayat-ayat al-Qur'an sendiri yang mendorong lahirnya perbedaan penafsiran. Di dalam alQur'an pesan etis selalu saja terselubungi oleh isyarat- isyarat yang menuntut penafsiran dan perenungan oleh manusia. ${ }^{6}$

Menurut Asy'ariyah, etika murni selalu bersifat subjektif, artinya bisa bermakna dengan adanya subjek, dalam hal ini adalah Allah. Satu-satunya tujuan bertindak moral ialah mematuhi Allah. Berbeda dengan Mu'tazilah, mereka berpendapat bahwa semua perintah Allah benar adanya, dan sifat benarnya terpisah dari perintah Allah. Dia memerintahkan kita untuk melakukan sesuatu yang benar lantaran memang benar adanya, berdasarkan landasan objektif bukan pada perintah Allah. Allah tidak bisa menuntut kita melakukan sesuatu yang tidak benar karena aturan moralitas bukanlah hal yang berada di bawah kendali-Nya. Memang, Dia lebih tau tindakan mana yang mesti dilakukan oleh kita, dan kita mesti terus mencari bimbingan-Nya. ${ }^{7}$

Asy'ariyah (teolog tradisional) memandang moralitas berada di bawah kontrol Allah, atau dengan pengertian lain moralitas itu mengandaikan agama. Akan tetapi, kalangan Mu'tazilah (teolog rasional) berpandangan sebaliknya. Mereka memandang moralitas adalah sebuah tindakan rasional manusia dalam melihat mana yang baik dan mana yang buruk, tidak semata-mata ditentukan oleh tuntutan agama. Secara umum tujuan etika bukan hanya mengetahui pandangan (theory), bahkan setengah dari tujuannnya ialah mempengaruhi dan mendorong kehendak kita, supaya membentuk hidup suci dan menghasilkan kebaikan dan kesempurnaan, dan memberi faedah kepada sesama manusia. Maka dari itu, etika ialah

${ }^{5}$ Al-Baihaqiy, Sunan al-Baihaqiy (Mekkah: Dar al-Baz, 1994), hlm. 191. \& M. Amin Abdullah, Antara Al-Ghazali dan Kant: Filsafat Etika Islam (Bandung : Mizan, 2002), hlm.15.

${ }^{6}$ Al-Sahmarani, As'ad. Al-Akhlāq fi al-Islām wa al-Falsafah al-Qadīmahal (Beirut: Daral-Nufais, 1994), hlm. 17. \& Al-Qur'an berulangkali menuntut pembacanya agar berjihad dengan menggunakan akalnya untuk menangkap pesan-pesan etis yang terkandung di dalamnya. Oleh karenanya adalah hal yang logis saja bahwa dalam sejarah Islam selalu terjadi perbedaan dan konflik intelektual yang dinamis antara sesama ahli pikir

${ }^{7}$ Oliver Leaman, Pengantar Filsafat Islam: Sebuah Pendekatan Tematis, Cet. II (Bandung: Mizan, 2002), hlm. 127. 
mendorong kehendak agar berbuat baik, akan tetapi ia tidak selalu berhasil kalau tidak ditaati oleh kesucian manusia. ${ }^{8}$

Aristoteles berkata: apa yang berhubungan dengan keutamaan tidak cukup dengan diketahui apakah keutamaan itu?, Bahkan harus ditambah dengan melatihnya dan mengerjakannya, atau mencari jalan lain untuk menjadikan kita orang-orang yang utama dan baik. Apabila pidato dan buku-buku itu dengan sendirinya dapat menjadikan kita orang baik, tentu sebagaimana dikatakan oleh Teognis hendaknya tiap manusia mengejar keutamaan dan sanggup membelinya dengan harga yang mahal sekali. Akan tetapi sayang segala dasar-dasar dalam soal itu hanya dapat dihasilkan dengan kekuatan kemauan sebagian angkatan muda untuk tetap dalam kebaikan dan hati yang mulia menurut fitrahnya dijadikan kawan bagi keutamaan, dan setia pada janji-janjinya. ${ }^{9}$

Tujuan etika dalam pandangan filsafat adalah "idealitas" yang sama bagi seluruh manusia di setiap waktu dan tempat dalam usaha untuk mencapai tujuan ini, etika mengalami kesukaran oleh karena fisik dan anggapan orang terhadap perbuatan itu baik atau buruk yakni sangat relatif sekali, karena setiap orang atau golongan mempunyai konsepsi tersendiri. Selain itu etika menentukan ukuran tingkah laku yang baik dan yang buruk sejauh yang dapat diketahui oleh akal manusia. Pola hidup yang diajarkan Islam bahwa seluruh kegiatan peribadatan, hidup, dan mati adalah semata-mata dipersembahkan kepada Allah, maka tujuan terakhir dari segala tingkah laku manusia menurut pandangan etika Islam adalah keridhaan Allah. ${ }^{10}$

Islam berpihak pada teori etika yang bersifat fitri. Artinya semua manusia (baik itu muslim atau bukan) memiliki pengetahuan fitri tentang baik dan buruk. Tampaknya, para pemikir Islam dari berbagai pendekatan sepakat tetang ini, Namun, sebagian diantaranya tidak sepakat. seperti Mu'tazilah dan para filsuf pada umumnya percaya bahwa manusia mampu memperoleh pengetahuan tentang etika yang benar dari pemikiran mereka. Sementara kaum Asy'ariah, para ulama hukum, dan kaum mistikus (ortodoks) lebih menekankan pada peran wahyu sebagai saran untuk mencapai pengetahuan etika manusia. Moralitas dalam Islam didasarkan kepada keadilan, yakni menempatkan segala sesuatu pada porsinya. Tanpa merelatifkan etika itu sendiri, nilai suatu perbuatan di yakini bersifat relatif terhadap konteks dan tujuan perbuatan itu sendiri. Mencuri, misalnya, bisa dinilai terlarang, tapi juga bisa dinilai sunnah, bahkan wajib.

Tindakan etis itu sekaligus dipercayai pada puncaknya akan menghasilkan kebahagiaan bagi pelakunya. Seperti yang disinggung di atas, tindakan etis itu bersifat rasional. Kaum rasionalis muslim tak bisa sependapat dengan anggapan (sebagaimana dilontarkan Kant, meskipun dalam banyak masalah kefitrian dorongan etis pendapatnya justru sejalan dengan Islam) bahwa menggunakan nalar dalam merumuskan etika akan mengakibatkan perselisihan pendapat yang tak pernah bisa disatukan. Justru, menurut mereka, Islam sangat percaya pada rasionalitas sebagai alat dalam mendapatkan kebenaran. Di sinilah Kant bersesuaian dengan al-Ghazali. Keduanya lebih menekankan pada faktor kewajiban (yang satu berdasarkan nalar

\footnotetext{
${ }^{8}$ Ahmad Amin, Ilmu Akhlak, alihbahasa Farid Ma'ruf (Jakarta: Bulan Bin- tang, 1991), hlm. 6-7.

${ }^{9}$ Ibid.,hlm. 7.

${ }^{10}$ Barmawi Umary, Materi Akhlak (Jakarta: Ramadhani, 1988), hlm. iii.
} 
praktis, sedangkan yang lain berdasarkan wahyu) sebagai tindakan etis. Keduanya pun sepakat bahwa etika lebih primer dari pada metafisika. ${ }^{11}$

\section{Pandangan Filsuf Muslim Tentang Etika}

* Al-Farabi

Konsep etika yang ditawarkan al-Farabi dan menjadi salah satu hal penting dalam karya-karyanya, berkaitan erat dengan pembicaraan tentang jiwa dan politik. Begitu juga erat kaitanya dengan persoalan etika ini adalah persoalan kebahagiaan. Di dalam kitab at-Tanbih fi Sabili al-Sa'adah dan Tanshil al-Sa'adah, al-Farabi menyebutkan bahwa kebahagiaan adalah pencapaian kesempurnaan akhir bagi manusia, al-Farabi juga menekankan empat jenis sifat utama yang harus menjadi perhatian untuk mencapai kebahagiaan di dunia dan di akhirat bagi bangsa-bangsa dan setiap warga negara, yakni keutamaan teoretis, keutamaan pemikiran, keutamaan akhlak, dan keutamaan amaliah. Menurut al-Farabi, kebahagiaan adalah pencapaian kesempurnaan akhir bagi manusia. Dan itulah tingkat akal mustafad, dimana ia siap menerima emanasi seluruh objek rasional dari akal aktif. Dengan demikian, perilaku berpikir adalah perilaku yang dapat mewujudkan kebahagiaan bagi manusia. Manusia mencapai kebahagiaan dengan perilaku yang bersifat keinginan. Sebagian di antaranya berupa perilaku kognitif dan sebagian lain berupa perilaku fisik, serta bukan dengan semua perilaku yang sesuai, tetapi dengan perilaku terbatas dan terukur yang berasal dari berbagai situasi dan bakat yang terbatas dan terukur. ${ }^{12}$

\section{* Ibnu Miskawaih}

Moral, etika atau akhlak menurut Ibnu Miskawaih adalah sikap mental yang mengandung daya dorong untuk berbuat tanpa berpikir dan pertimbangan. Sikap mental terbagi dua, yaitu yang berasal dari watak dan yang berasal dari kebiasan dan latihan. Akhlak yang berasal dari watak jarang menghasilkan akhlak yang terpuji, kebanyakan akhlak yang jelek. Sedangkan latihan dan pembiasaan lebih dapat menghasilkan akhlak yang terpuji. Karena itu Ibnu Miskawaih sangat menekankan pentingnya pendidikan untuk membentuk akhlak yang baik. Dia memberikan perhatian penting pada masa kanak-kanak, yang menurutnya merupakan mata rantai antara jiwa hewan dengan jiwa manusia. Inti kajian akhlak, menurut Ibnu Miskawaih adalah kebaikan (al-khair), kebahagiaan (al-sa'adah), dan keutamaan (al-fadilah). Kebaikan adalah suatu keadaan dimana kita sampai kepada batas akhir dan kesempurnaan wujud. Kebaikan ada dua, yaitu kebaikan umum dan kebaikan khusus. Kebaikan umum adalah kebaikan bagi setiap atau seluruh manusia dalam kedudukannya sebagai manusia, atau dengan kata lain ukuran-ukuran kebaikan yang dapat disepakati oleh seluruh manusia. Kebaikan khusus adalah kebaikan bagi seseorang secara pribadi. Kebaikan yang kedua inilah yang disebut kebahagiaan. Karena itu dapat dikatakan bahwa kebahagiaan itu berbeda-beda bagi setiap orang. ${ }^{13}$

\section{* Al-Ghazali}

Etika atau akhlak menurut pandangan al-Ghazali bukanlah pengetahuan (ma'rifah) tentang baik dan jahat atau kemauan (qudrah) untuk baik dan buruk, bukan pula pengamalan (fi'il) yang baik dan jelek, melainkan suatu keadaan jiwa yang mantap. Al-Ghazali

\footnotetext{
${ }^{11}$ Abdullah, Amin. Antara al-Ghazali dan Kant: Filsafat Etika Islam. IRCISOD, 2002.

${ }^{12}$ Muhammad 'Ustman Najati. Jiwa dalam Pandangan para Filosof Muslim (Bandung : Pustaka Hidayah, 1993), hlm. 76.

${ }^{13}$ Hasyimsyah Nasution, Filsafat Islam ( Jakarta: Gaya Media Pratama, 2005), hlm. 64-66.
} 
berpendapat sama dengan Ibn Miskawaih bahwa penyelidikan etika harus dimulai dengan pengetahuan tentang jiwa, kekuatan dan sifat-sifatnya. Tentang klasifikasi jiwa manusia pun al-Ghazali membaginya ke dalam tiga hal yaitu daya nafsu, daya berani, dan daya berpikir, sama dengan Ibn Miskawaih. ${ }^{14}$

Dalam Ihya' Ulum al-Din, Imam al-Ghazali mengungkapkan pandangan-pandangan etikanya yaitu sebagai berikut: Pertama, akhlak berarti mengubah bentuk jiwa dari sifat yang buruk kepada sifat yang baik sebagaimana perangai ulama, syuhada', shiddiqin, dan para nabi. Oleh karenanya, al-Ghazali mengedepankan konsep tashfiyat al-nafs (penjernihan jiwa) sebagai proses pembersihan hati dari berbagai sifat yang madzmumah, dan takmil al-nafs (penyempurnaan jiwa) dengan berbagai sifat yang mahmudah. Kedua, Akhlak yang baik dapat mengadakan pertimbangan antara tiga kekuatan dalam diri manusia, yaitu kekuatan berpikir, kekuatan hawa nafsu, dan kekuatan amarah. Akhlak yang baik sering kali menentang apa yang digemari manusia. Ketiga, Akhlak itu adalah kebiasaan jiwa yang tetap dan juga terdapat dalam diri manusia yang secara mudah dan tanpa perlu berpikir menumbuhkan perbuatan dan tingkah laku manusia. Apabila lahir tingkah laku yang indah dan terpuji, maka dinamakan akhlak baik, dan apabila yang lahir itu tingkah laku yang keji, dinamakanlah akhlak yang buruk. ${ }^{15}$

Dan adapun salah satu ulama sufi dan pemikir mistik teosof yang banyak mengajarkan tentang etika dan filasafat adalah Syekh Muhammad Yusuf Al-Makassari. Ia merupakan salah satu ulama dan juga pahlawan nusantara bahkan dunia yang dalam perjuangannya menyebarkan agama Islam menjadi tonggak bersejarah bagi seorang putra daerah Gowa. Konsep etika atau moral dari ajaran Syekh Yusuf secara substantif berbasis pada prinsip "al takhalluq bi akhlaq Allah" (berakhlak dengan akhlak Allah). Etika yang diajarkan sufi seperti Syekh Yusuf bersifat komprehensif, substantif dan universal. Syekh Yusuf sendiri berkali-kali menekankan perlunya menerapkan "husnul khuluk" (akhlak luhur) baik terhadap Tuhan maupun terhadap makhluk. Akhlak yang baik atau luhur haruslah bersifat utuh, lengkap dan tercermin dalam seluruh penampilan pribadi seseorang yang mencakup sikap, sifat, perkataan, perbuatan atau prilaku yang timbul dari hati yang bersih. ${ }^{16}$

\section{PENUTUP}

Dalam perspektif filsafat, etika dipahami sebagai sebuah refleksi filosofis tentang moral, etika lebih merupakan wacana normatif, tetapi tidak selalu harus imperatif, karena bisa juga hipotesis, yang membicarakan pertentangan antara yang baik dan yang buruk, yang dianggap sebagai nilai relatif dalam pandangan rasional manusia dalam bertindak. Etika juga dapat dipandang sebagai seni hidup yang mengarah kepada kebahagiaan dan memuncak kepada kebijakan. Sedangkan dalam kacamata filsafat Islam, etika sarat dengan muatan teologis, nilai kebaikan berdasarkan al-Qur'an dan sunnah. Berawal dari landasan epistemologi religius tersebut konsep etika dalam Islam dikembangkan sedemikian rupa sehingga mampu mendorong seseorang melakukan perbuatan yang baik, karena etika merupakan sebuah rambu-rambu didalam bertindak yang akan membimbing dan

\footnotetext{
${ }^{14}$ Mahjuddin, Kuliah Akhlak-Tasawuf (Jakarta: Kalam Mulia, 1994), hlm. 21.

${ }^{15}$ Lihat, Imam al-Ghazali, Ihya 'Ulum al-Din, vol 10. Lihat juga, M. Abul Quasem, Etika alGhazali: Etika Majemuk di dalam Islam, terjemahan. J. Mahyudin (Bandung: Pustaka, 1988), hlm. 81-82.

${ }^{16}$ Sainuddin, Ibnu Hajar, and Ismail Suardi Wekke. "Syekh Yusuf Al-Makassari: Pandangan Etika dan Filsafat." (2020), hlm. 1. \& Mustari, Belajar Etika Kepada Syekh Yusuf Al-Makassari,(2020).hlm.145
} 
mengingatkan seseorang untuk melakukan perbuatan yang bernilai dan yang bermanfaat yang harus selalu dipatuhi dan dilaksanakan karena membawa kemaslahatan bersama. Hal itu sebagaimana dijelaskan dalam pemikiran etika al-Farabi, Ibnu Miskawaih, dan al-Ghazali yang berorientasi lebih pada kebahagiaan dan keselamatan individu di dunia dan akhirat berdasarkan doktrin agama. Dan juga pemikiran Syekh Yusuf Al-Makassari yang menekankan etika atau moral itu sangatlah penting bagi pribadi seseorang.

\section{DAFTAR PUSTAKA}

Sainuddin, Ibnu Hajar, and Ismail Suardi Wekke. "Syekh Yusuf Al-Makassari: Pandangan Etika dan Filsafat." (2020).

Taufik, M. (2016). Etika dalam Perspektif Filsafat Islam. Etika: Teori, Praktik, dan Perspektif, edited by Zuhri, 35-64.

Dewantara, Agustinus. "Filsafat Moral (Pergumulan Etis Keseharian Hidup Manusia)." (2017).

Bertens, K. (1993). Etika K. Bertens (Vol. 21). Gramedia Pustaka Utama.

Sainuddin, Ibnu Hajar, Muhammad Arsyam, and Ismail Suardi Wekke. "Syekh Yusuf AlMakassari; Pengembangan Masyarakat Islam.” (2020)

Sulhin, I. (2012). Filsafat (sistem) pemasyarakatan. Jurnal Kriminologi Indonesia, 7(1).

Syafi'i, M. (2018). Etika dalam Pandangan Al-Farabi. Jurnal Ilmiah Ilmu Ushuluddin, 16(2), 139-160.

Hamim, N. (2014). Pendidikan Akhlak: Komparasi Konsep Pendidikan Ibnu Miskawaih dan Al-Ghazali. Ulumuna, 18(1), 21-40.

Sainuddin, Ibnu Hajar, and Ismail Suardi Wekke. "Islamisasi Kerajaan Gowa." (2020).

Suryadarma, Yoke, and Ahmad Hifdzil Haq. "Pendidikan akhlak menurut imam Al-Ghazali." At-Ta'dib 10.2 (2015).

Hakim, A. (2016). Filsafat Etika Ibn Miskawaih. Jurnal Ilmiah Ilmu Ushuluddin, 13(2), 135143.

Mahmud, Akilah. “Akhlak Islam Menurut Ibnu Miskawaih.” Aqidah-Ta: Jurnal Ilmu Aqidah, $6.1(2020)$.

Arsyam, Muhammad,and Ibnu Hajar Sainuddin."Meraih Surga dengan Sabar dan Syukur."

Effendi, R. (2017). Filsafat Kebahagiaan (Plato, Aristoteles, Al-Ghazali, Al-Farabi). Deepublish.

Mulyasana, D. Konsep Etika Belajar dalam Pemikiran Pendidikan Islam Klasik.

Abdullah, Amin. Antara al-Ghazali dan Kant: Filsafat Etika Islam. IRCISOD, 2002.

Sarwoto, S. (2013). "Pandangan Al-Ghazali Tentang Pendidikan Moral." Al-Mabsut: Jurnal Studi Islam dan Sosial, 6(1), 46-67.

Sainuddin, Ibnu Hajar, Muhammad Arsyam, and Andi Muhammad Shaleh Alwi. "Pemahaman Makna Tauhid dan Dua Kalimat Syahadat." (2020). 